\title{
The Role of Circulation and Land Surface Conditions in Current and Future Australian Heat Waves ${ }^{\circ}$
}

\author{
Peter B. Gibson And Andrew J. Pitman \\ Climate Change Research Centre, and ARC Centre of Excellence for Climate System Science, \\ University of New South Wales, Sydney, New South Wales, Australia \\ RUTH LORENZ \\ Institute for Atmospheric and Climate Science, ETH Zürich, Zurich, Switzerland \\ SARAH E. PERKINS-KIRKPATRICK \\ Climate Change Research Centre, and ARC Centre of Excellence for Climate System Science, \\ University of New South Wales, Sydney, New South Wales, Australia
}

(Manuscript received 25 April 2017, in final form 18 August 2017)

\begin{abstract}
Understanding the physical drivers of heat waves is essential for improving short-term forecasts of individual events and long-term projections of heat waves under climate change. This study provides the first analysis of the influence of the large-scale circulation on Australian heat waves, conditional on the land surface conditions. Circulation types, sourced from reanalysis, are used to characterize the different large-scale circulation patterns that drive heat wave events across Australia. The importance of horizontal temperature advection is illustrated in these circulation patterns, and the pattern occurrence frequency is shown to reorganize through different modes of climate variability. It is further shown that the relative likelihood of a particular synoptic situation being associated with a heat wave is strongly modulated by the localized partitioning of available energy between surface sensible and latent heat fluxes (as measured through evaporative fraction) in many regions in reanalysis data. In particular, a several-fold increase in the likelihood of heat wave day occurrence is found during days of reduced evaporative fraction under favorable circulation conditions. The atmospheric circulation and land surface conditions linked to heat waves in reanalysis were then examined in the context of CMIP5 climate model projections. Large uncertainty was found to exist for many regions, especially in terms of the direction of future land surface changes and in terms of the magnitude of atmospheric circulation changes. Efforts to constrain uncertainty in both atmospheric and land surface processes in climate models, while challenging, should translate to more robust regional projections of heat waves.
\end{abstract}

\section{Introduction}

Heat waves severely impact multiple aspects of society and the economy (Guo et al. 2014; Burke et al. 2015; Horton et al. 2016). When aggregated over large spatial scales, climate models consistently project future increases in the frequency of heat wave days in many

Supplemental information related to this paper is available at the Journals Online website: https://doi.org/10.1175/ JCLI-D-17-0265.s1.

Corresponding author: Peter B. Gibson, peter.gibson@unsw.edu. regions under a high greenhouse gas emissions scenario (Fischer et al. 2013). Both thermodynamic and dynamical contributions play an important role in how heat waves respond to a changing climate. For example, while background warming has begun to cause a shift in the temperature distribution toward more hot extremes (and fewer cold extremes) (Donat and Alexander 2012), regional changes in large-scale circulation (Wallace et al. 2012; Horton et al. 2015; Deser et al. 2016; Mann et al. 2017) and soil moisture trends (Lorenz et al. 2016) can influence higher statistical moments of the distribution.

Observational and modeling studies, focused largely on Europe and the United States, have demonstrated the combined role of atmospheric and land surface 
processes in influencing heat waves (e.g., Quesada et al. 2012; Miralles et al. 2014; Teng et al. 2016). Indeed, Quesada et al. (2012) provided observational evidence that background soil moisture conditions in the lead up to summer modulate the influence of the atmospheric circulation on summer European hot days. Focusing on the recent 2003 and 2010 "mega-heat waves" of Europe, Miralles et al. (2014) found that both the persistent circulation patterns linked to the advection of warmer air and a multiday progressive accumulation and entrainment of heat in the boundary layer linked to soil desiccation were important in explaining the heat wave intensity. Using multiple runs from a single climate model, Teng et al. (2016) found that future changes in U.S heat waves respond more strongly to land surface conditions than changes in atmospheric circulation characteristics.

In regions where land surface processes affect heat waves and temperature extremes (Seneviratne et al. 2010, 2016), model projections can disagree on how relevant processes may change (e.g., Lorenz et al. 2016) thereby contributing to uncertainty in future heat wave trends. Similarly, in the atmosphere, any long-term regional changes in large-scale circulation features, including changes to blocking and horizontal temperature advection, would influence the nature of heat waves. Unfortunately, state-of-the-art climate models commonly underestimate blocking frequency (e.g., Scaife et al. 2010; Anstey et al. 2013) and often disagree on the statistics of regional large-scale circulation features (Pastor and Casado 2012; Gibson et al. 2016). This uncertainty often persists into future projections where models can disagree on changes in circulation-related variables in many regions (Shepherd 2014). Taken together, uncertainty related to future changes in atmospheric and land surface processes contributes to uncertainty in heat wave trends, warranting further investigation on a region-by-region basis.

For Australian heat waves, both large-scale circulation (e.g., Pezza et al. 2012; Parker et al. 2013; Purich et al. 2014; Marshall et al. 2014) and land surface conditions (e.g., Perkins et al. 2015; Herold et al. 2016; Perkins-Kirkpatrick et al. 2016) have been shown to be important drivers. However, these two components have previously been studied in isolation; otherwise, the focus has been directed toward individual heat wave event occurrences for a particular region (PerkinsKirkpatrick et al. 2016). For example, Nicholls and Larsen (2011) examined observational data for Melbourne and found a discernible increase in daily maximum temperatures following periods of drought under favorable circulation conditions. Kala et al. (2015), using regional climate model simulations of a single heat wave event, found that soil moisture conditions in northern Australia influenced heat waves in the south of Australia by altering the overall dynamics over short lead times. Important dynamical distinctions also exist for Australian heat waves. In many Northern Hemisphere regions the role of highly persistent collocated blocking events is dominant (e.g., Pfahl and Wernli 2012), whereas for much of Australia the horizontal advection of warm dry air over relatively short time periods is particularly important (Pezza et al. 2012; Purich et al. 2014; Gibson et al. 2017a).

Statistically significant positive trends in heat wave characteristics are found in observational data for many regions of Australia, although the magnitudes of these trends vary regionally (Perkins and Alexander 2013; Perkins-Kirkpatrick et al. 2016; Gibson et al. 2017b). Large-scale modes of climate variability, including the southern annular mode (SAM) and El Niño-Southern Oscillation (ENSO), have also been studied in relation to Australian heat waves (Parker et al. 2014; Perkins et al. 2015; Loughran et al. 2017). In observational data, Perkins et al. (2015) observed the largest positive heat wave associations in northern and eastern regions of Australia under summer El Niño conditions. In contrast, the positive phase of the SAM was found to be associated with fewer heat wave days in eastern regions of Australia and a slightly greater number of heat wave days in southern regions. Although these statistical associations have been identified, research focused on understanding the mechanisms that link large-scale modes of climate variability to Australian heat waves is ongoing (e.g., Parker et al. 2014; Loughran et al. 2017).

This study investigates how Australian heat waves respond differently to atmospheric circulation patterns conditional upon the state of the land surface. A logistic regression framework is applied to represent these linkages (section 2). These linkages are then used to evaluate how future changes in atmospheric and land surface conditions in climate models may influence the nature of Australian heat waves (sections 3 and 4). The main findings are summarized in section 5 .

\section{Methods}

\section{a. Heat wave calculations}

The Modern-Era Retrospective Analysis for Research and Applications version 2 (MERRA-2) (Bosilovich et al. 2015) was used to calculate heat waves on a grid point basis. For purposes of maintaining internal consistency, MERRA-2 data were also used to examine atmospheric and land surface processes over the period 1980-2015 (described below). MERRA-2 includes a number of updates from the original MERRA reanalysis product, including the use of observation-based (merged satellite and gauge) precipitation data to correct the 


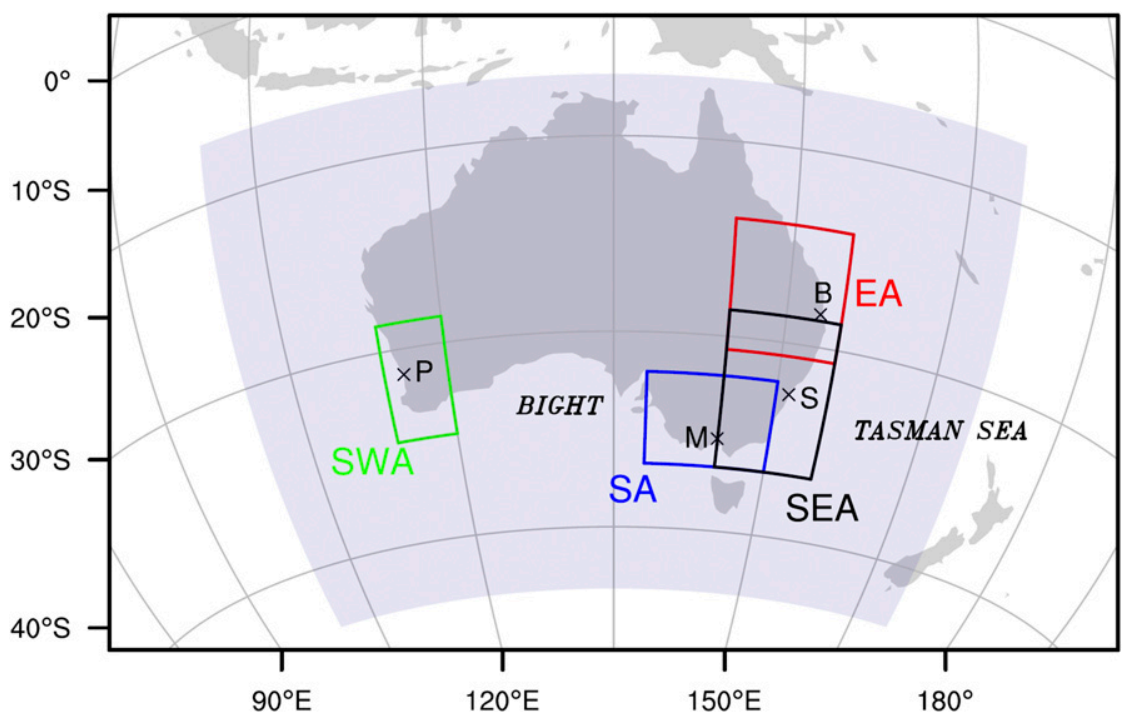

FIG. 1. Map detailing regions and major cities referred to in this study. The larger region from which the SOM was trained is shaded gray. Other regions include southwestern Australia (SWA), southern Australia (SA), southeastern Australia (SEA), and eastern Australia (EA). These smaller regions of Australia were determined based on links between circulation and heat wave occurrence (described in section 3). Cities shown are Perth (P), Melbourne (M), Sydney (S), and Brisbane (B).

precipitation falling over land. These improvements provide more observationally constrained estimates of the land surface, including better estimates of soil moisture (Reichle et al. 2017). The excess heat factor (EHF) (Nairn and Fawcett 2015) definition of heat waves was employed, which is based on daily average (average of daily maximum and minimum) temperature exceeding the 90th percentile of the base period daily temperature for 3 calendar days (as in Perkins and Alexander 2013). The base period temperature percentiles are computed from a 15-day moving window over the period 1980-2004. We follow the convention that the Australian summer heat wave season comprises the period from November to March (NDJFM) (e.g., Perkins and Alexander 2013).

Comparisons were also made to other heat wave definitions outlined in Perkins and Alexander (2013); however, our results were found to be relatively insensitive to the particular choice of heat wave definition (not shown) so we give focus to EHF. The daily maximum and minimum temperature data were linearly detrended prior to the calculation of heat waves so that the known nonstationarity associated with recent warming would not unduly influence the associations with other variables to be investigated (described below).

\section{b. Atmospheric circulation patterns}

Atmospheric circulation patterns were analyzed through a self-organizing map (SOM) approach applied to MERRA-2 daily mean sea level pressure (MSLP) fields in NDJFM over the Australian domain $\left(10^{\circ}-50^{\circ} \mathrm{S}\right.$, $100^{\circ}-170^{\circ} \mathrm{E}$; see Fig. 1). The MSLP fields were first regridded to an Equal-Area Scalable Earth (EASE) type grid at a spatial resolution of $\sim 100 \mathrm{~km}$ to ensure that SOM input vectors are weighted by the appropriate grid cell area. Second, the area-averaged MSLP (over the Australian domain) at each daily time step was removed from the MSLP field. This was carried out so that the SOM patterns are more directly focused toward variability in the MSLP gradients (related to horizontal temperature advection) compared with the domain mean.

Gibson et al. (2017a) recently evaluated the suitability of SOMs to characterize large-scale circulation during extreme events for the region and found suitable performance for heat waves even for a relatively small-sized SOM (i.e., using a small number of SOM patterns). In particular, when using a small-sized SOM (e.g., six SOM patterns/nodes) the circulation patterns that co-occur during heat waves were found to be represented with comparable accuracy to the typical circulation represented by the SOM patterns. In contrast, for other types of extremes (e.g., heavy rainfall and midlatitudinal cyclone occurrence days) a considerably larger number of SOM patterns was needed to represent the concurrent circulation in sufficient detail. Given this, our results are presented for a six-node SOM, since this reasonably represents the main large-scale circulation features relevant to heat waves in the Australian region. Larger-sized 
SOMs (e.g., 12 nodes) showed similar linkages to heat wave occurrence, indicating that results are robust to this choice as described below. The use of a smaller number of SOM patterns also ensured that a relatively large sample size was retained per node pattern; this was important since node occurrences were later analyzed using subsets of different land surface conditions.

The particular SOM training approach employed may be considered a $\mathrm{SOMs} / K$-means hybrid training approach. This was shown to perform favorably compared to more traditional approaches adopted in synoptic climatology in terms of producing realistic circulation patterns (Gibson et al. 2017a). The procedure implements a neighborhood radius that decreases linearly to 1 in the first half of training and then is fixed at 1 . By fixing the neighborhood to 1 , only the winning node is updated (comparable to $K$ means), as opposed to the winning node and surrounding nodes. This allows more targeted refinement of the earlier patterns to be obtained. This approach also tends to produce patterns with a higher average dissimilarity and can represent patterns that occur more rarely, but with reduced topological ordering in the SOM plane. Gibson et al. (2017a) provide further discussion of this SOM training and its relevance for studying climate extremes, and Hewitson and Crane (2002) provide a background review of the application and value of SOMs to climate research.

Near-surface horizontal temperature advection calculated from MERRA-2 data was analyzed under particular SOM patterns and heat wave occurrences:

$$
\mathbf{V} \cdot \nabla T=u\left(\frac{\partial T}{\partial x}\right)+v\left(\frac{\partial T}{\partial y}\right)
$$

The wind vector field $\mathbf{V}$ with components $u, v$ was calculated from 3-hourly, 10-m wind components, and the temperature gradient field $\nabla T$ was calculated from 3-hourly, 2-m temperature using spherical harmonic functions applied to global data. To analyze the upperlevel circulation, daily 500-hPa geopotential anomaly height fields from MERRA-2 were also analyzed, where the anomalies were calculated by removing the long-term monthly mean from each daily field.

\section{c. Modes of large-scale climate variability}

Different phases of ENSO were identified from the monthly Southern Oscillation index (SOI) from the Australian Bureau of Meteorology (see the acknowledgments). Phases of the SAM were identified from the station-based SAM index based on the zonal pressure difference between the latitudes of $40^{\circ}$ and $65^{\circ} \mathrm{S}$ from the British Antarctic Survey (see the acknowledgments). As in Jiang et al. (2013) (and references therein), La Niña events were identified by monthly SOI $\geq 7$ and El Niño events by $\mathrm{SOI} \leq-7$; positive SAM events were identified by monthly $S A M \geq 1$ and negative SAM events by $\mathrm{SAM} \leq-1$.

\section{d. Evaporative fraction}

Evaporative fraction (EF) captures the role of the land surface in terms of the partitioning of available energy between sensible and latent heat fluxes consequential on a moistening or drying of the surface. Daily EF was calculated from MERRA-2 data:

$$
\mathrm{EF}=\frac{Q_{E}}{Q_{E}+Q_{H}},
$$

where $Q_{E}$ and $Q_{H}$ are the latent and sensible heat fluxes, respectively. We defined four EF spatial regions broadly reflecting where large-scale circulation patterns were shown to predominately influence heat wave occurrence. These regions, southwestern Australia (SWA), southern Australia (SA), southeastern Australia (SEA), and eastern Australia (EA), also contain high population densities of cities (Perth, Melbourne, Sydney, Brisbane) affected by heat waves (see Figs. 1 and 2). Since it was found that a particular circulation pattern can significantly influence the heat wave likelihood over a broad geographical region, particularly on the southern east coast, the EF regions were chosen to allow for some overlap between regions (Fig. 1). Daily area-averaged EF was then calculated from each of these regions and then separated into terciles to provide a daily index of general land surface conditions in that region. Terciles were used in this calculation to ensure that a relatively large sample size was retained when these occurrences were later analyzed in combination with different node patterns. Low (high) EF days for a particular region were defined as days when the area-averaged EF was below (above) the lower (upper) terciles.

\section{e. Logistic regression}

The associations between heat waves, atmospheric circulation types, and EF were represented by odds ratios modeled through logistic regression. The odds ratio is computed as the odds that an outcome will occur (i.e., heat wave day) given a particular exposure or combination of exposures (i.e., particular SOM node pattern) relative to the odds that an outcome will occur in the absence of exposure(s). Examples of logistic regression in climate research include understanding associations between precipitation and wind extremes (Martius et al. 2016), antecedent precipitation and floods (Froidevaux et al. 2015), and 


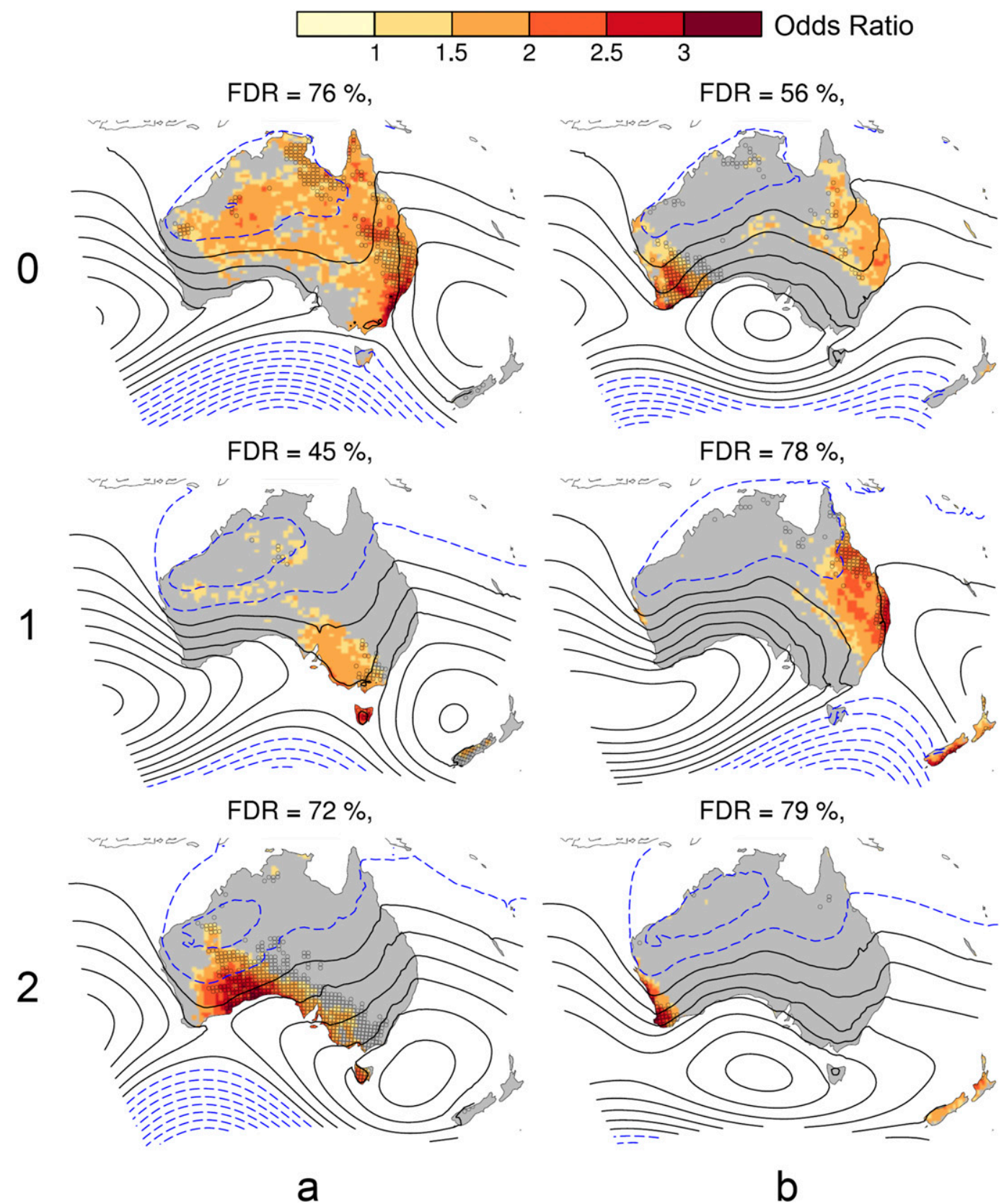

FIG. 2. Heat wave odds ratio by circulation type, defined by nodes from (top left) a0 to (bottom right) b2 obtained from the SOM procedure described in section 2. A darker shade indicates a higher relative likelihood of heat wave occurrence when a particular circulation type occurs. Only odds ratios greater than 1 and significant $(p<0.05)$ are shown. The percentage of shaded values significant above the FDR criterion is given for each circulation type. Stippling indicates locations where a 2-day or more persistent circulation type has a higher relative likelihood $(p<$ 0.05 ) of heat wave occurrence compared to a transient (1 day) circulation type. MSLP contours are at 2-hPa intervals and contours less than $1010 \mathrm{hPa}$ are dotted blue to distinguish regions of relatively low pressure.

extratropical jet position and extreme events (Mahlstein et al. 2012).

Odds ratios are calculated by fitting three separate logistic regression models (M1-M3). The general form of these models follows

$$
\ln \left(\frac{p_{i}}{1-p_{i}}\right)=\beta_{0}+\beta_{1} X_{1}+\beta_{2} X_{2}+\cdots+\beta_{n} X_{n},
$$

where the left side of Eq. (3) is the logit (log of the odds) of a heat wave day occurring; the right side is a linear 
combination of categorical predictor variables $X_{1}, \ldots$, $X_{n}$ where the corresponding $\beta_{1}, \ldots, \beta_{n}$ coefficients, when exponentiated, represent the relative contribution to the odds of heat wave occurrence.

We build models from Eq. (3) by selecting predictor variables $X_{1}, \ldots, X_{n}$ to separately address three research questions. First, do circulation types influence the likelihood of heat wave occurrence differently (M1)? Second, does circulation type persistence influence this likelihood (M2)? Third, do land surface conditions (as represented through EF) modulate this likelihood (M3)?

Model M1 included a single independent variable $X_{1}$ that is a binary variable representing the occurrence of the circulation type of interest on day $t$. This approach is comparable to that described in Röthlisberger et al. (2016), who analyzed the occurrence of various types of climate extremes under conditions of "jet waviness." Model M2 also included a single independent variable $X_{1}$ but with levels: $X_{1}=0$ where the circulation type of interest does not occur on day $t, X_{1}=1$ where the circulation type occurs on day $t$ but not on day $t-1$, and $X_{1}=2$ where the circulation type occurs on both day $t$ and on day $t-1$. By comparing the $\beta$ coefficients [Eq. (3)] between levels we determine the relative influence of circulation type persistence, with Wald's statistic (Wald 1943) used to evaluate the significance of this difference. Last, model M3 follows M1 but a second binary variable $X_{2}$ is added representing whether or not the region-specific area-averaged EF is below the lower terciles on day $t$. A third term was included in M3 to model the interaction between variables $X_{1}$ and $X_{2}$, as discussed by Chen (2003). This approach allows us to examine how, given a particular circulation type occurrence $X_{1}$, the land surface conditions $X_{2}$ may alter the likelihood of heat wave occurrence. Each model was fitted separately to each grid point for the given set of conditions described.

The false discovery rate approach (FDR) to field significance (Wilks 2016) was employed to evaluate the significance of the odds ratio fields and the $t$-test fields. The FDR approach requires local tests (of all the tests calculated per grid point) to be significant above a certain threshold by controlling the expected proportion of local null hypotheses that are falsely rejected. Here, we choose the FDR control level as 5\%. If none of the local tests is significant beyond the FDR then the field significance criteria is deemed not to be met.

\section{f. Climate model data}

Daily surface flux and MSLP data from various models participating in the Coupled Model Intercomparison Project phase 5 (CMIP5) were also analyzed (shown in
Fig. S1 in the online supplemental material). Changes in the frequency of regional low EF days and changes in the frequency of particular SOM patterns were analyzed comparing time periods 1965-2000 and 2065-2100. Data for the 1965-2000 period were taken from the historical experiment with models forced by observed atmospheric composition changes from both natural and anthropogenic sources. Data for the period 2065-2100 were taken from the representative concentration pathway (RCP8.5) representing high radiative forcing associated with minimal climate change mitigation. Because of data availability, the number of models differed slightly between the EF and SOM analysis, with 25 models and 28 models analyzed, respectively (see Fig. S1). The analysis of projected changes in both EF and SOMs, carried out separately, allowed consideration of the model spread in each of these conditions to highlight potential sources of model uncertainty.

The SOM circulation types found in MERRA-2 were used as a "master SOM" (section 2b), and climate model data were mapped onto this. In particular, each daily MSLP field from individual climate models was mapped to a single node from the master SOM through minimizing the Euclidean distance measure. Repeating this mapping across all days in a particular dataset (i.e., an individual climate model) enabled frequency changes in circulation types to be calculated on a per-model basis comparing historical and RCP8.5 scenarios. As with the master SOM, the model data were first regridded to the same EASE grid, and the data were centered (domain area-average removed from the MSLP field). The EF index was calculated for climate models as described in section $2 \mathrm{~d}$ where the EF terciles were derived from the distributions of EF in each region per model. A small number of grid points displayed physically unrealistic EF values (i.e., values above 1 and below 0 ) in some model simulations and were masked prior to the calculations; this was shown to have very little influence on subsequent results.

To study internal variability in the context of future projections, we also include an independent set of simulations from the Community Earth System Model (CESM) version 1.0.4. By internal variability we refer to the model-generated internal variability as related to unforced changes in the climate system. These simulations were produced by inducing very small random perturbations (on the order of $10^{-13}$ ) to the initial conditions of the atmospheric temperature field to provide a 20-member ensemble [see Fischer et al. (2013) for further details]. This allows the influence of internal variability to be studied more directly by removing parametric and structural uncertainties associated with the larger CMIP5 model ensemble. Future projections 
of circulation and EF in this CESM initial-condition ensemble were calculated as for the CMIP5 ensemble described earlier.

\section{Results}

\section{a. Circulation linkages}

The association between different circulation types and heat wave day occurrence is shown in Fig. 2, where nodes $\mathrm{a} 0$ and $\mathrm{b} 0$ are given in the first row, nodes a 1 and $\mathrm{b} 1$ in the second row, and nodes $\mathrm{a} 2$ and $\mathrm{b} 2$ in the third row. By comparing odds ratios (shaded colors) between node patterns in Fig. 2 we illustrate how the association between circulation and the likelihood of heat wave day occurrence differs for various regions across Australia. Heat waves in region EA are associated with a relatively weak high pressure system in the Tasman Sea and a trough extending into southern Australia (node b1). In parts of this region, the circulation represented by this node typically increases the odds of a heat wave by as much as 4 times compared to other circulation types. Heat waves in SEA are related to a stronger high pressure system in the Tasman Sea with warm northwesterly winds (node a0). Similarly, heat waves in SA are related to a high pressure system in the Tasman Sea but with a low pressure trough positioned farther south and with winds more directly from the north (nodes a1 and a2). Last, SWA heat waves are linked to high pressure in the Bight (see Fig. 1) and warm northeasterly winds (nodes b0 and b2). Where the association is relatively strong in these regions, slower-moving (i.e., more persistent) circulation features further increase the heat wave occurrence likelihood, as indicated by the stippled regions in Fig. 2.

Sensitivity testing to a larger-sized SOM (12 nodes) reveals very similar linkages between circulation and heat wave occurrences, but with slightly greater detail in the atmospheric circulation patterns for certain nodes (Fig. S2). For example, the strength and position of the trough over southern Australia can further increase the circulation association with heat waves in EA (comparing nodes $\mathrm{c} 0$ and $\mathrm{c} 3$ in Fig. S2).

The frequency of circulation types occurring in the summer heat wave season was found to be reorganized under different phases of ENSO and SAM (Fig. 3). Nodes a 0 and b1, related to an increased likelihood of heat wave day occurrence in SEA and EA, significantly increase in frequency during El Niño conditions compared with typical conditions and also significantly decrease during La Niña conditions. Node a0 also increases in frequency during negative SAM conditions and decreases during positive SAM conditions. This

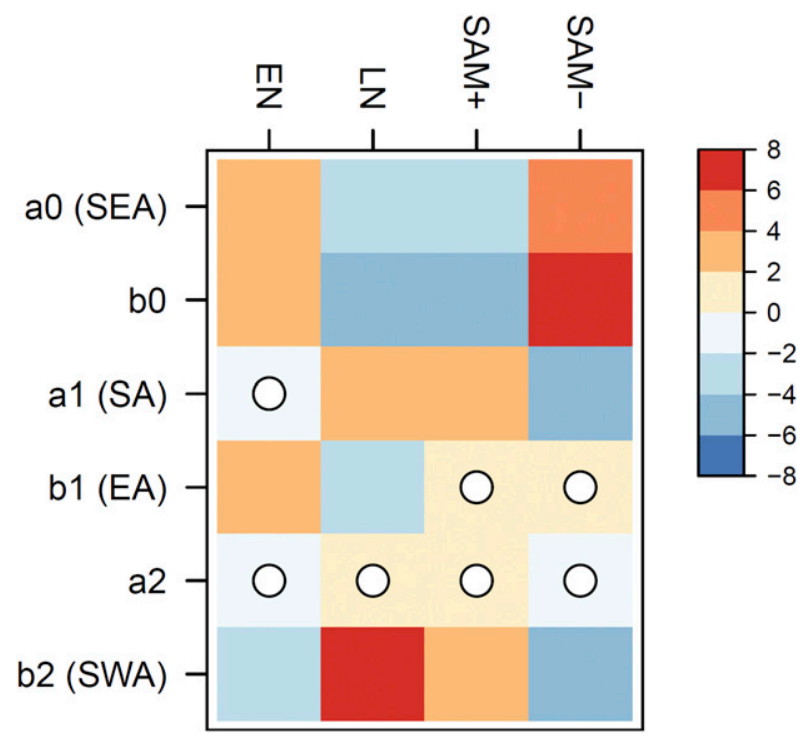

FIG. 3. Summary plot displaying associations between El Niño (EN), La Niña (LN), positive SAM (SAM+), and negative SAM (SAM-) and the frequency occurrence of SOM circulation types (shown in Fig. 2) over the period 1980-2015. Colors indicate the difference between the percentage of circulation type frequency occurrence under the particular ENSO/SAM conditions and the percentage of circulation type frequency occurrence under all (i.e., typical) conditions. Positive values therefore indicate that a particular circulation type occurs more frequently under a given ENSO/SAM condition than typical for that circulation type. Circles indicate no evidence of a significant difference (i.e., $p>0.05$ ) in proportions for the two-proportions $z$ test.

reorganization of circulation conditions during ENSO/ SAM conditions is consistent with the positive ENSO correlation and negative SAM correlation for heat wave day frequency across the SEA and EA regions, which were found to be the strongest in Perkins et al. (2015). It is interesting that heat wave associations with ENSO/ SAM were found to be relatively weak across SWA in Perkins et al. (2015) despite the strong influence of La Niña conditions on the frequency of node b2 reported here (Fig. 3); this suggests that other important drivers are relevant in SWA. None of the circulation types examined displayed strong statistically significant trends in frequency of occurrence for the heat wave season over the historical study period (Fig. S3).

The links between circulation and heat wave occurrence (Fig. 2) suggest an important role for horizontal temperature advection with relatively warm dry air, often from the continental interior, advected toward cooler coastal locations under an offshore wind direction. In the subsequent analysis we select a subset of nodes based on the highest odds ratios (Fig. 2) across the regions and cities of interest in Fig. 1 (the subset is a0, a1, b1, and b2) and analyze composites of daily maximum 
$\mathrm{a} 0$

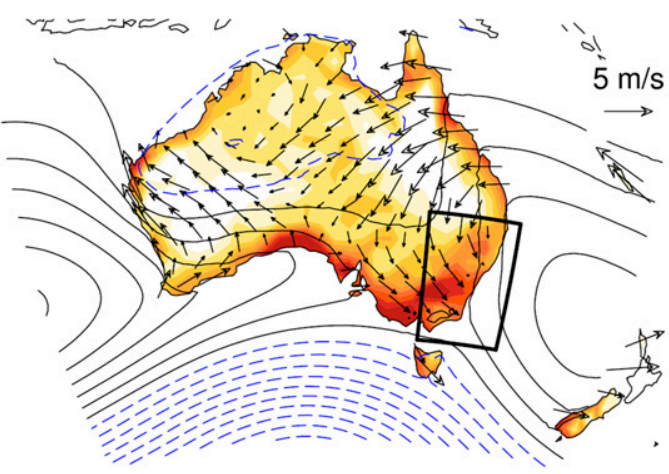

b1

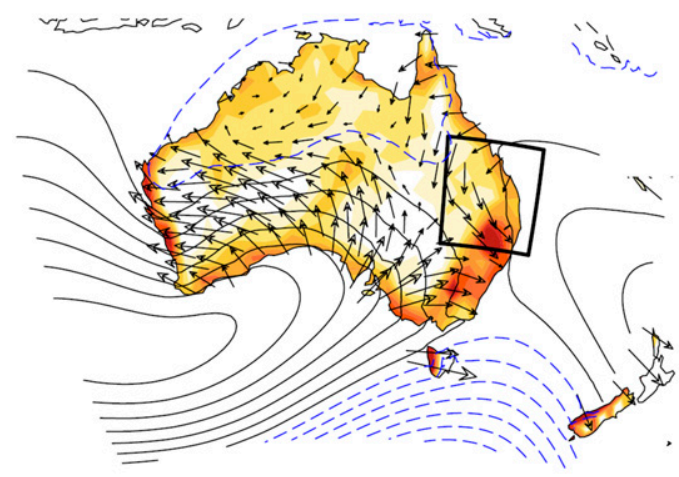

a1

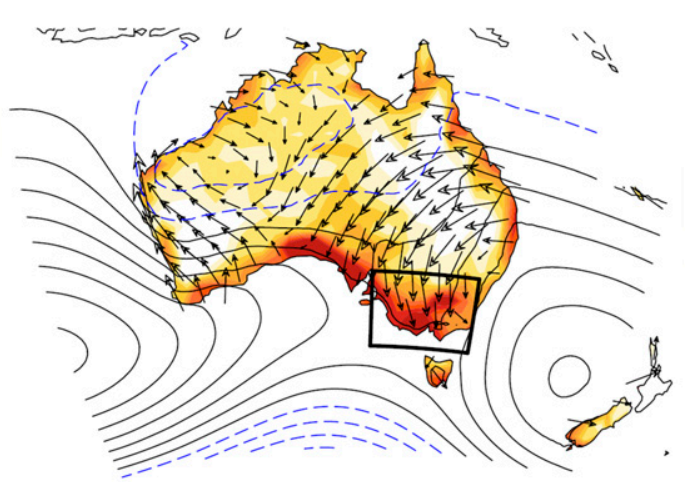

b2

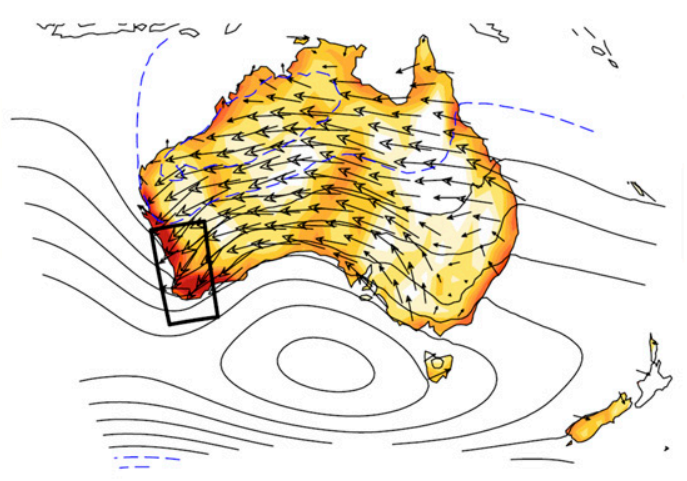

$\boldsymbol{V} \cdot \nabla T$

FIG. 4. Composites of maximum horizontal temperature advection [Eq. (1); ${ }^{\circ} \mathrm{C} \mathrm{day}^{-1}$ ] and $10-\mathrm{m}$ wind speed and direction for selected circulation types from Fig. 2. Composites are calculated from days when both the circulation type occurs and $50 \%$ or more of the boxed area is experiencing a heat wave day. The daily maximum horizontal temperature advection is calculated from the maximum of the subdaily 3-hourly data.

horizontal advection. As shown in Fig. 4, when widespread heat waves occur in each of these regions, the daily maximum temperature advection is large and typically collocated where a higher likelihood of heat waves was shown in Fig. 2. For example, for SEA, node $\mathrm{a} 0$ represents relatively warm northwesterly airflow over the heat wave region. Similarly, for SA, northerly airflow advects heat from relatively warm and dry regions (see section $3 b$ ) into the heat wave region. One notable exception to this is under node b1 (i.e., for heat waves in the EA region) where heat waves in the south of this region appear more strongly linked to temperature advection compared with heat waves in the north. This is associated with the more marine source of advection in the north and a more continental source in the south.

\section{b. Circulation and EF linkages}

Using the node subset examined in Fig. 4, we then explored how the state of EF may modulate the likelihood of a particular circulation type influencing a heat wave. An odds ratio significantly greater than 1 in Fig. 5 indicates locations where low EF further enhances the likelihood of heat wave occurrence when a particular circulation type occurs. For example, during warm northwest wind conditions (node a0) combined with low EF the likelihood of heat wave occurrence in many locations across SEA increases several fold, in comparison to node a0 co-occurring with higher EF conditions (i.e., EF conditions not in the lower terciles defined for that region).

Relatively low EF (relative for that region) greatly enhances the circulation heat wave association, particularly in SEA, and also in parts of EA and SA. The likelihood of a heat wave under favorable synoptic conditions can be increased by 8 times under low EF conditions. The influence of EF is least apparent in SWA, where many grid points are not statistically significant in terms of the odds ratio. 

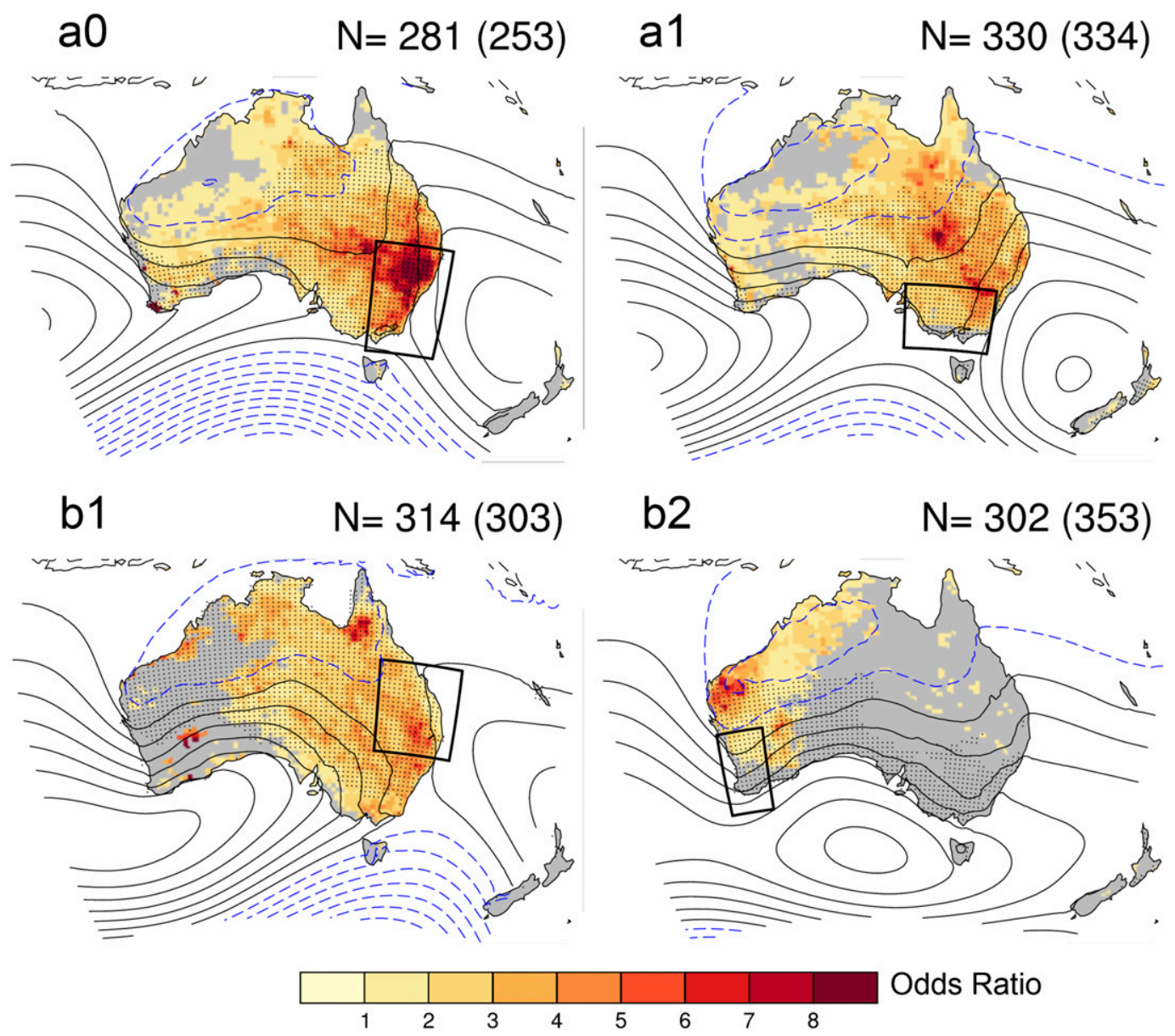

FIG. 5. Odds ratio of heat wave occurrence for circulation types shown in Fig. 4 but for low EF conditions under favorable synoptic conditions. An odds ratio greater than 1 indicates that low EF increases the likelihood of a particular circulation type inducing a heat wave. Stippling indicates other locations where the EF is also lower than average (at that grid point) when the region averaged EF is in the lower terciles, as determined by a $t$ test. Significance of both odds ratios and $t$ tests was determined by the FDR at $95 \%$ significance. The number of days $N$ when the SOM pattern occurs and low (high) EF occurs is given above each panel.

Notable differences in the area-averaged distributions of EF also exist between regions. For SWA the distribution is more heavily skewed, with lower variance, and relatively high EF values (i.e., $>0.5$ ) are rarer (Fig. S4). This reflects the arid and semiarid regional climate where most rainfall occurs in winter months, and these regional and seasonal differences in moisture availability may contribute to the weaker association between circulation and EF for SWA. In other words, since this region is typically dry anyway (relative to other regions), particular days that are drier than normal are unlikely to add to the likelihood of heat wave occurrence.

Although the area-averaged EF was calculated for specific regions (i.e., the boxed regions in Fig. 5), spatial dependence within the EF fields in Fig. 5 ensures that nearby regions can also experience relatively low EF when the EF in the boxed region was classified as low. In many grid points outside of the boxed regions where the heat wave odds ratio was significantly higher than 1 , local $t$ tests (i.e., stippled grid points in Fig. 5) also confirm that EF is significantly lower than average for that grid point. This likely explains the more widespread spatial extent of these significant odds ratios, as apparent along much of the east coast of Australia and farther inland.

Since not all daily synoptic conditions should be considered identical for a given circulation type, we explored whether the large-scale circulation patterns were sufficiently different during low EF occurrences to partly explain the associations found. In general, for a given circulation type, the differences in MSLP between low EF day composites and the typical circulation type MSLP composites were small and often statistically 
(a)

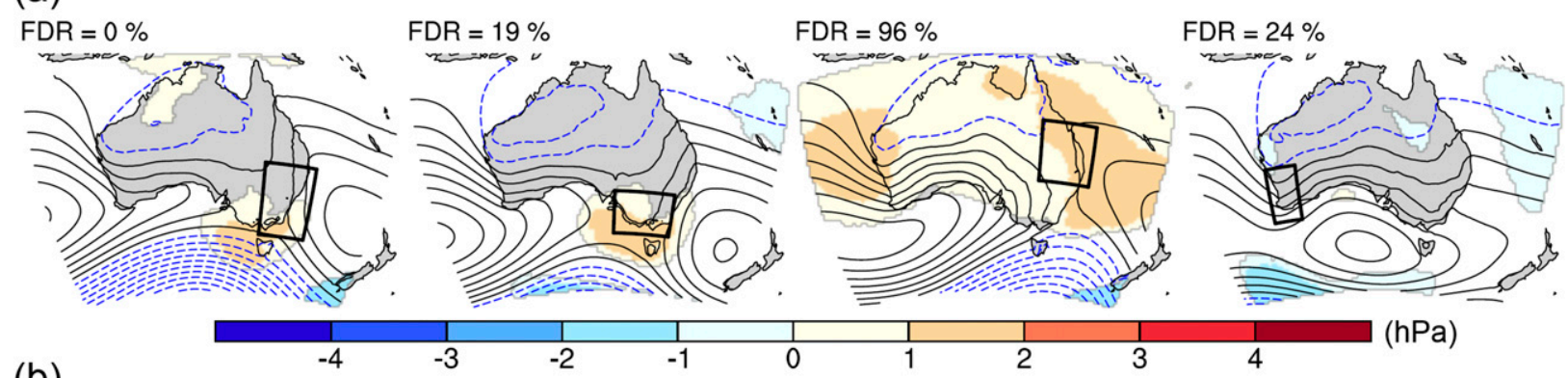

(b)

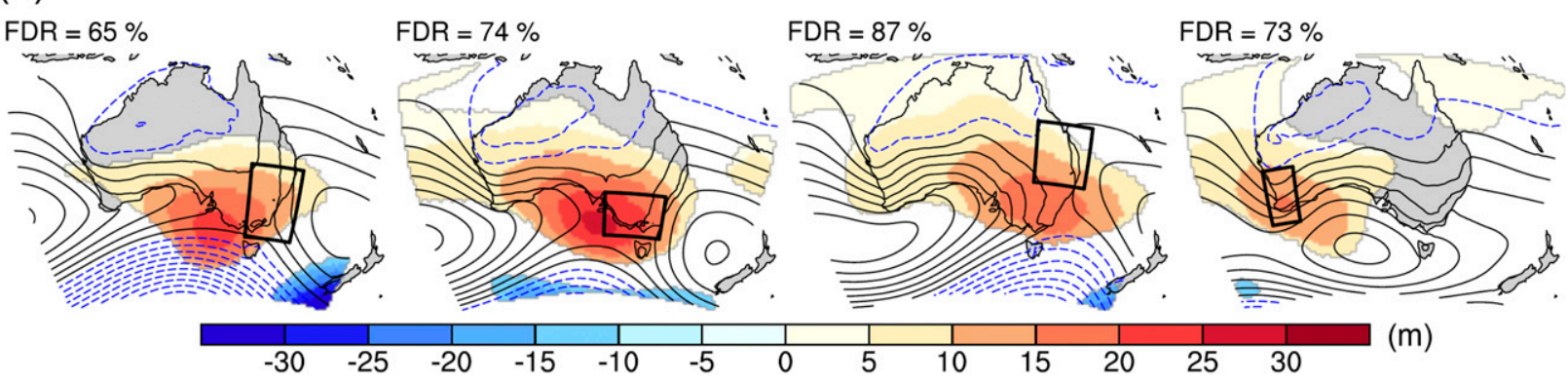

FIG. 6. (a) Difference in MLSP for selected circulation types (Fig. 4) between low EF occurrences and "all days." Positive values indicate that MSLP is larger during low EF occurrences. Only differences where $p<0.05$ determined by a $t$ test are shown, and the percentage of local $t$ tests that meet the FDR criteria are given. Where FDR $=0 \%$ the field significance criteria are not met. (b) As in (a), but for geopotential height anomalies (z500).

insignificant $(<2 \mathrm{hPa})$ (Fig. 6a). The number of days a particular circulation type occurred across the study period was also similar under the different EF classifications (Fig. 5). These results suggest that the association between EF and heat waves (Fig. 5) is not simply the result of differences in MSLP.

For the circulation at z500 (Fig. 6b), differences are larger compared with MSLP where more neighboring grid points display significantly higher geopotential heights at times of low EF. This could point toward a strengthening of the upper-level ridge during low EF that may act to enhance surface warming (i.e., positive feedback). For this to hold, this difference or intensification should not occur on the first few days of low EF but rather at later lag times when the low EF gradually develops to influence the upper-level circulation. Indeed, during the first few days of a particular low EF/ circulation type co-occurrence, the differences at the z500 level are typically insignificant according to the field significance criterion in the boxed region (Fig. S5), the exception being SWA where significant increases in geopotential height occur more immediately (i.e., on days 1-3). An alternate explanation to this feedback could simply be that longer-lived geopotential height anomalies are associated with lower rainfall by blocking rain-bearing circulation features, thereby leading to extended periods of low EF (even if these anomalies were typically not the cause of low EF to begin with). While it is difficult to draw definitive conclusions from reanalysis/observations in terms of separating the cause from the effect, our results provide evidence that $\mathrm{z} 500$ is not likely a strong confounder in the found association between EF and heat waves. Furthermore, in SWA the association between EF and heat waves was not significant in many grid cells, and so z500 cannot be implicated.

\section{c. Climate model projections}

Given the linkages between circulation, EF, and heat waves found in reanalysis, we then examined future projections in these driving conditions in CMIP5 models (Fig. 7). In terms of circulation changes (Fig. 7a), the CMIP5 ensemble provided consistent projections ( $90 \%$ or more of models agree on directional change) of a decrease in the frequency of heat wave-conducive patterns in SEA and an increase in frequency for SA and SWA. However, even when models agree on the direction of these circulation changes there is typically very large spread in the magnitude. For example, for heat wave-conducive patterns in SA, the median model projection is an increase in frequency of $24 \%$ but some models project the occurrence of this pattern to more than double (e.g., HadGEM2-ES > 120\%; Fig. S1).

In terms of EF, there is typically lower consensus in the model ensemble regarding directional changes 
(a)

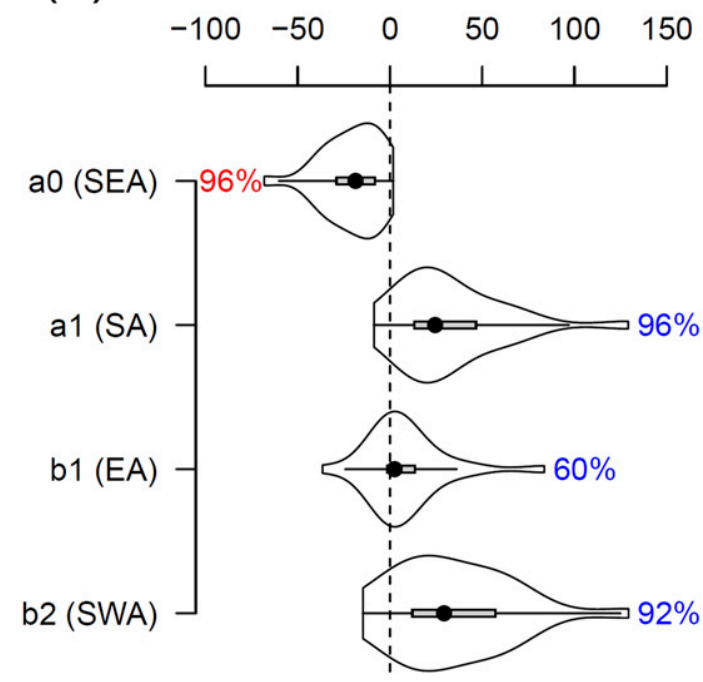

(b)

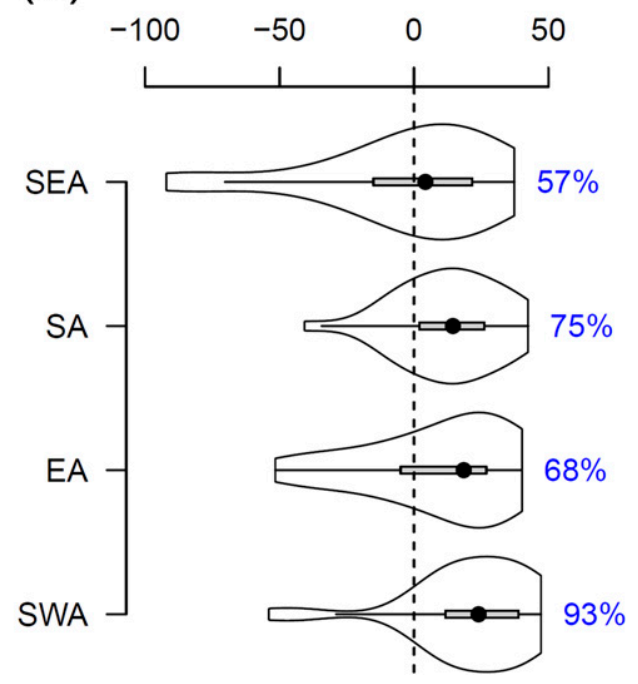

FIG. 7. (a) Future percentage changes (2065-2100 minus 1965-2000) in CMIP5 for different SOM pattern occurrences that influence heat waves in particular regions (given in parentheses; see Fig. 4). The red (blue) percentages indicate the percentage of models in the ensemble that agree on negative (positive) signed changes. (b) As in (a), but for future changes in the frequency of low EF day occurrences by region.

(Fig. 7b). The median change in the occurrence of days of relatively low EF (shown earlier to be linked to higher heat wave likelihood in many regions) is positive for all regions (i.e., more days of relatively dry conditions), but the model consensus is typically weak and regionally dependent. For example, in SEA only $57 \%$ of models agree on this increased frequency of dry conditions, in contrast to SWA where $93 \%$ of models project an increase. These results are insensitive to how EF values were masked in the CMIP5 models (Fig. S6).

Some of these reported changes may be due to internal variability in the climate system and others due to parametric or structural differences in the CMIP5 models. To examine this, we evaluated 20 runs from the CESM model. These are run with the same forcings but with different initial conditions to allow different trajectories of low-frequency variability to occur. Figure 8a provides evidence that some of the projections in atmospheric circulation may be due to unforced internal variability. In particular, the SWA and SEA regions exhibit reasonably consistent projections in the presence of internal variability (with negative and positive frequency changes, respectively), yet the changes in frequency in SA and EA are less consistent. For EF changes in the CESM runs, different runs also project inconsistent directional changes owing to internal variability. The SWA region again stands out in terms of exhibiting the highest degree of consistency in the projection of an increase in low EF days.
Examining the CESM model projections over longer time periods ( $50 \mathrm{vs} 35 \mathrm{yr}$ ) yields similar results but with a slight reduction in variability (Fig. S7). In general the circulation and EF projections from CESM (both positive and negative) are on the lower side of those found in the CMIP5 ensemble (Fig. 7a). This may mean that internal variability is more capable of competing with the generally small forced changes in CESM compared to other models in the CMIP5 ensemble (lower signal-tonoise ratio).

\section{Discussion}

The linkages between large-scale circulation and heat wave occurrence reported here are in broad agreement with previous findings despite major differences in methodological approaches (e.g., Pezza et al. 2012; Purich et al. 2014). In particular, previous studies have used composite analysis, a different (earlier generation) reanalysis product, and a slightly different heat wave definition. Our results are also in very good agreement with Gibson et al. (2017a), who used a different reanalysis product and examined heat waves from a gridded product derived solely from station temperature measurements. These agreements, despite methodological differences, indicate robustness in linking largescale circulation to heat wave occurrence and the role of horizontal temperature advection. The use of circulation types also enabled a closer examination of the ENSO/SAM heat wave associations presented in 
(a)

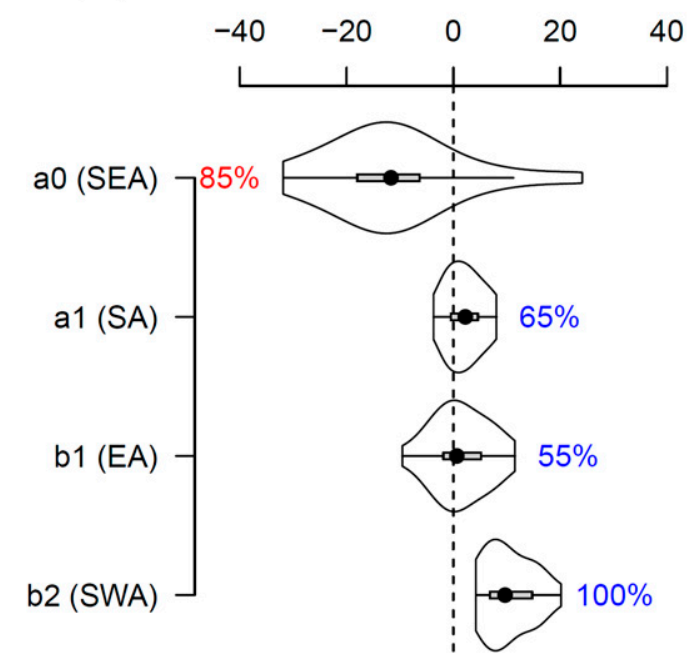

(b)

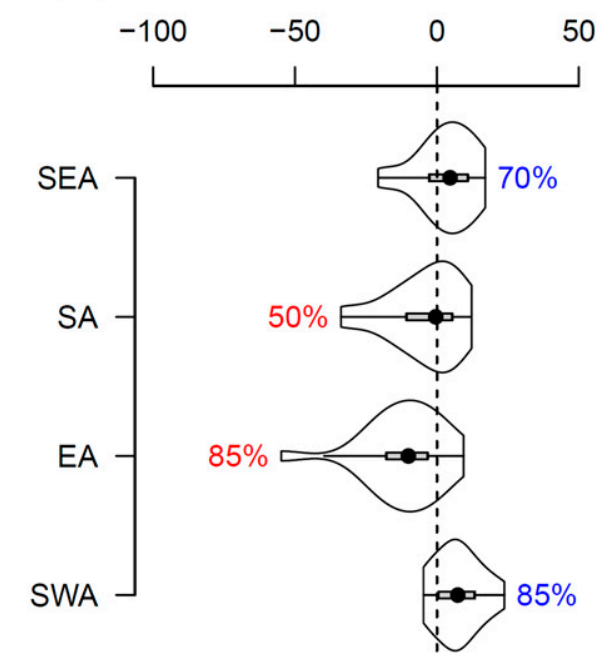

FIG. 8. (a) As in Fig. 7a (SOM pattern occurrence) and (b) as in Fig. 7b (low EF occurrence) but for 20 initialcondition runs of the CESM model.

Perkins et al. (2015). As described in section 3a, our results suggest that the reorganization of the frequency of heat wave-relevant circulation patterns under different ENSO/SAM phases contributes to the strongest regional heat wave associations described in Perkins et al. (2015).

Persistent circulation patterns are also shown to increase the likelihood of heat wave occurrence in many parts of Australia. Given the relevance to heat waves, mechanisms that influence the persistence of particular circulation conditions in this region require further investigation. For example, Parker et al. (2013) presented evidence that tropical cyclones in northwestern Australia may reinforce the strength and persistence of high pressure systems to influence heat waves in the SA region. Similar targeted examinations in other parts of Australia may add further detail to the understanding of how circulation influences heat waves and also be useful in providing a process-based evaluation of heat waves in climate models.

In terms of land surface fluxes, low EF conditions in SEA and parts of SA and EA can greatly enhance the likelihood of heat waves; in contrast, limited association between low EF and heat wave occurrence in SWA was found. The results are in broad agreement with similar previous studies. Herold et al. (2016) found strong negative correlations between the standardized precipitation evapotranspiration index (SPEI) and heat wave occurrence at 1-3-month lead times. Perkins et al. (2015) performed a similar analysis using standardized rainfall anomalies over longer lead times (up to the preceding 5 months of the heat wave season) and found similar spatial patterns to those reported in Herold et al. (2016) but with stronger correlations in eastern Australia.

Previous studies did not examine the influence of land surface conditions on heat waves conditional upon the larger-scale circulation. An important distinction is that we have shown both the occurrence of favorable circulation and low EF is important to heat wave occurrence. Therefore, particular years with frequent conditions of enhanced evaporative cooling (i.e., "wetter" years) likely offset the influence of high relative frequency of circulation features favorable for heat wave development. These results extend the findings of Nicholls and Larsen (2011), which are specific to Melbourne (in region SA), to multiple regions across Australia, thereby allowing comparisons to be made between regions. Notably, the association between land surface conditions and heat waves during favorable circulation conditions appears stronger in many other regions compared to Melbourne, which was studied in Nicholls and Larsen (2011).

Analyzing future CMIP5 projections of circulation and EF conditions conducive to heat waves highlights large uncertainties. In particular, a large spread in the magnitude of future circulation changes and disagreement in the direction of future EF change was shown across the model ensemble. As such, it seems that narrowing the uncertainty in projections of circulation and EF will be required to narrow uncertainty in regional heat wave projections. Analysis of a CESM initial condition ensemble suggests that the influence of internal variability can add to the uncertainty of circulation and 
EF changes. For example, in some regions different runs give rise to different directional changes, indicating that internal variability can compete in magnitude with the forced response. However, since the forced response (i.e., the median change in the CESM runs) was typically on the lower end of changes in circulation and EF found in the CMIP5 ensemble, comparisons with multiple initial condition runs from other models would be useful.

Since model consistency in projections appears regionally dependent, we briefly discuss possible implications for regional heat wave projections. A slight decrease in the frequency of node a0 (indicated by the multimodel median) and increase in the frequency of nodes $\mathrm{a} 1$ and $\mathrm{b} 2$ would suggest a slight decrease in the occurrence of heat waves in SEA and increases in SA and SWA. Based on EF, the most consistent projections occur for SWA, where $93 \%$ of CMIP5 model runs analyzed agree on future decreases in EF. This "drying trend" for SWA has been reported in other recent studies examining CMIP5 projections of soil moisture (e.g., Cheng et al. 2017). However, this is also where the $\mathrm{EF}$ association to increased likelihood of heat waves under favorable synoptic conditions was not found to be strong (except along the north coast of western Australia). A reasonably large number of models (75\%) also agree on a higher incidence of low EF in SA in future projections. In combination with the projected slight increase in the frequency of circulation conditions conducive to heat waves for SA, this suggests that heat waves in SA could be influenced more than other regions into the future under a favorable combination of circulation and land surface changes projected by CMIP5 models.

It is important to note that any possible changes (either positive or negative), and associated uncertainties, should be thought of as additional changes to the already positive thermodynamic changes in heat waves under global warming (e.g., Cowan et al. 2014), to which higher confidence can be placed. Any "secondary" changes (e.g., changes to circulation or EF) may translate to changes in both heat wave frequency and intensity in a future warmer climate. As heat waves become more common in a warmer climate, the dynamical setup may not need to be as intense to induce a heat wave (Purich et al. 2014), but under these favorable conditions a greater number of intense heat waves would be expected. Therefore, the projections reported here for SA are broadly aligned with model projections showing largest increases in heat wave intensity in this region (Cowan et al. 2014). While greater uncertainty exists for other regions, there is no strong evidence that positive changes to heat waves associated with mean-state warming may be offset by substantial circulation or land surface changes projected by the CMIP5 ensemble.
A number of caveats and opportunities to extend this work exist. First, the reliable simulation of EF in MERRA-2 is clearly important to our results. Unfortunately, long-term reliable eddy covariance measurements of surface fluxes are sparse in this region. In addition, comparisons between gridded reanalysis surface fluxes, comprised of large grid point averages, and point-based measurements are difficult. However, it is encouraging that the results presented here are in broad agreement with both Perkins et al. (2015) and Herold et al. (2016), who used different methods and observational products to infer the role of the land surface on heat waves. It would be useful to repeat this type of analysis when newer reanalysis products become available and land surface representations continue to be updated.

Although we have found no strong evidence for significant differences in the MSLP circulation under low $\mathrm{EF}$, differences were larger at the $\mathrm{z} 500$ level at longer lag times. Further targeted model experiments are required before determining with confidence that low EF conditions provide a positive feedback by intensifying an upper-level ridge to influence Australian heat waves, in general. While Kala et al. (2015) presented evidence of an intensification of the upper-level ridge under prescribed (decreased) soil moisture conditions in targeted model experiments for Australia, the analysis focused on a single intense (i.e., rare) heat wave event for a particular region, and it is difficult to generalize this result to more moderate heat waves in other parts of Australia.

Another challenge for models in the CMIP5 ensemble, which we have not examined here, is that the correct linkages between circulation, $\mathrm{EF}$, and heat waves need to be represented. In models where these associations bear little resemblance to the real world, modelprojected changes to these drivers (as examined in this study) may not translate closely to heat wave projections in the model. The results from this study will provide a useful benchmark for model evaluation of this nature. This type of process-based model evaluation could also be used to form a subset of CMIP5 models used in future projections (e.g., Sippel et al. 2017) on the basis that these models simulate heat waves well and for the correct physical reasons. Refining model ensemble projections in this way may ultimately help constrain uncertainty in regional heat wave projections.

\section{Conclusions}

This study has examined the extent to which land surface turbulent energy fluxes modulate the association between atmospheric circulation patterns and heat 
waves across different regions of Australia. After evaluating the combined role of atmospheric circulation and $\mathrm{EF}$ in driving heat waves in reanalysis, we then examined future projections of these drivers in CMIP5 models. The main findings are the following:

- Under favorable synoptic conditions, horizontal temperature advection increases the likelihood of heat waves in many regions across Australia. Persistent circulation patterns (compared to more transient patterns) typically further increase the likelihood of heat wave occurrence. These results are aligned with previous studies linking circulation to heat waves, but extend the examination to many more regions across Australia (e.g., eastern and southeastern parts of Australia, relevant to Brisbane and Sydney) through the use of circulation types. Reorganization of the typical frequency of circulation types under ENSO and SAM phases also appears to contribute to the associations between heat waves and these modes of climate variability reported in previous studies.

- Land surface fluxes, associated with reduced evaporative cooling and enhanced sensible heating, can enhance the association between circulation and heat waves in some regions. The likelihood of heat wave occurrence under favorable synoptic conditions can be increased by as much as 8 times under low EF conditions in parts of SEA. These findings add to previous studies that have studied the influences of circulation and soil moisture on heat waves separately.

- Within the CMIP5 model ensemble, a large degree of uncertainty exists regarding changes in EF and circulation conditions. Projections of circulation conditions relevant to heat waves differ most notably in terms of the magnitude of change. Projections of EF differ in terms of direction reflecting major uncertainty in how soil moisture is projected to change (Lorenz et al. 2016). The degree of uncertainty is also regionally dependent. The majority of models in the ensemble project that future circulation ( $96 \%$ of models) and EF ( $75 \%$ of models) conditions will both positively influence heat waves in SA, with a higher frequency of warm northerly winds and a higher frequency of days with reduced evaporative fraction. There is little evidence to suggest changes in any region, of the opposite direction, would be sufficient to offset the positive influence of thermodynamic mean-state warming on heat waves.

The linkages reported here between circulation, EF, and heat waves should serve as a useful basis for model evaluation in future work. Given the degree of uncertainty found for CMIP5 projections of these drivers, constraining this uncertainty will be required to enable robust regional projections of Australian heat waves.
Acknowledgments. We thank the NCI National Facility at the Australian National University for providing data storage and computational facilities. We acknowledge the World Climate Research Programme's Working Group on Coupled Modelling, which is responsible for CMIP, and we thank the climate modeling groups for producing and making available their model output. Erich Fischer also kindly provided the CESM initial condition model ensemble. MERRA-2 data used in this study is produced by NASA GMAO available from http://disc.sci.gsfc.nasa.gov/uui/datasets. Monthly SAM data were obtained from BAS at http://www.nerc-bas.ac. uk/public/icd/gjma/newsam.1957.2007.txt. Monthly SOI data were obtained from BOM at ftp://ftp.bom.gov.au/ anon/home/ncc/www/sco/soi/soiplaintext.html. This work was supported by the Australian Research Council (ARC) Centre of Excellence for Climate System Science Grant CE110001028. Author P.G. was supported by an Australian Postgraduate Award and author S.P.-K. supported by an ARC Discovery Early Career Researcher Award (DE140100952).

\section{REFERENCES}

Anstey, J. A., and Coauthors, 2013: Multi-model analysis of Northern Hemisphere winter blocking: Model biases and the role of resolution. J. Geophys. Res. Atmos., 118, 3956-3971, doi:10.1002/jgrd.50231.

Bosilovich, M. G., and Coauthors, 2015: MERRA-2: Initial evaluation of the climate. NASA Tech. Memo. NASA/TM-2015104606/Vol. 43, 145 pp., https://gmao.gsfc.nasa.gov/pubs/docs/ Bosilovich803.pdf.

Burke, M., S. M. Hsiang, and E. Miguel, 2015: Global non-linear effect of temperature on economic production. Nature, $\mathbf{5 2 7}$, 235-239, doi:10.1038/nature15725.

Chen, J., 2003: Communicating complex information: The interpretation of statistical interaction in multiple logistic regression analysis. Amer. J. Public Health, 93, 1376-1377, doi:10.2105/AJPH.93.9.1376-a.

Cheng, S., J. Huang, F. Ji, and L. Lin, 2017: Uncertainties of soil moisture in historical simulations and future projections. J. Geophys. Res. Atmos., 122, 2239-2253, doi:10.1002/2016JD025871.

Cowan, T., A. Purich, S. Perkins, A. Pezza, G. Boschat, and K. Sadler, 2014: More frequent, longer, and hotter heat waves for Australia in the twenty-first century. J. Climate, 27, 58515871, doi:10.1175/JCLI-D-14-00092.1.

Deser, C., L. Terray, and A. S. Phillips, 2016: Forced and internal components of winter air temperature trends over North America during the past 50 years: Drivers and implications. J. Climate, 29, 2237-2258, doi:10.1175/JCLI-D-15-0304.1.

Donat, M. G., and L. V. Alexander, 2012: The shifting probability distribution of global daytime and night-time temperatures. Geophys. Res. Lett., 39, L14707, doi:10.1029/2012GL052459.

Fischer, E., U. Beyerle, and R. Knutti, 2013: Robust spatially aggregated projections of climate extremes. Nat. Climate Change, 3, 1033-1038, doi:10.1038/nclimate2051.

Froidevaux, P., J. Schwanbeck, R. Weingartner, C. Chevalier, and O. Martius, 2015: Flood triggering in Switzerland: The role of 
daily to monthly preceding precipitation. Hydrol. Earth Syst. Sci., 19, 3903-3924, doi:10.5194/hess-19-3903-2015.

Gibson, P. B., P. Uotila, S. E. Perkins-Kirkpatrick, L. V. Alexander, and A. J. Pitman, 2016: Evaluating synoptic systems in the CMIP5 climate models over the Australian region. Climate Dyn., 47, 2235-2251, doi:10.1007/s00382-015-2961-y.

—, S. E. Perkins-Kirkpatrick, P. Uotila, A. S. Pepler, and L. V. Alexander, 2017a: On the use of self-organizing maps for studying climate extremes. J. Geophys. Res. Atmos., 122, 3891-3903, doi:10.1002/2016JD026256.

,,-- L. V. Alexander, and E. M. Fischer, 2017b: Comparing Australian heat waves in the CMIP5 models through cluster analysis. J. Geophys. Res. Atmos., 122, 3266-3281, doi:10.1002/ 2016JD025878.

Guo, Y., and Coauthors, 2014: Global variation in the effects of ambient temperature on mortality: A systematic evaluation. Epidemiology, 25, 781-789, doi:10.1097/EDE.0000000000000165.

Herold, N., J. Kala, and L. V. Alexander, 2016: The influence of soil moisture deficits on Australian heat waves. Environ. Res. Lett., 11, 064003, doi:10.1088/1748-9326/11/6/064003.

Hewitson, B., and R. Crane, 2002: Self-organizing maps: Applications to synoptic climatology. Climate Res., 22, 13-26, doi:10.3354/cr022013.

Horton, D. E., N. C. Johnson, D. Singh, D. L. Swain, B. Rajaratnam, and N. S. Diffenbaugh, 2015: Contribution of changes in atmospheric circulation patterns to extreme temperature trends. Nature, 522, 465-469, doi:10.1038/ nature 14550.

Horton, R. M., J. S. Mankin, C. Lesk, E. Coffel, and C. Raymond, 2016: A review of recent advances in research on extreme heat events. Curr. Climate Change Rep., 2, 242-259, doi:10.1007/ s40641-016-0042-x.

Jiang, N., G. Griffiths, and A. Lorrey, 2013: Influence of large-scale climate modes on daily synoptic weather types over New Zealand. Int. J. Climatol., 33, 499-519, doi:10.1002/joc.3443.

Kala, J., J. P. Evans, and A. J. Pitman, 2015: Influence of antecedent soil moisture conditions on the synoptic meteorology of the Black Saturday bushfire event in southeast Australia. Quart. J. Roy. Meteor. Soc., 141, 3118-3129, doi:10.1002/qj.2596.

Lorenz, R., and Coauthors, 2016: Influence of land-atmosphere feedbacks on temperature and precipitation extremes in the GLACE-CMIP5 ensemble.J. Geophys. Res. Atmos., 121, 607 623, doi:10.1002/2015JD024053.

Loughran, T. F., S. E. Perkins-Kirkpatrick, and L. V. Alexander, 2017: Understanding the spatio-temporal influence of climate variability on Australian heatwaves. Int. J. Climatol., 37, 3963 3975, doi:10.1002/joc.4971.

Mahlstein, I., O. Martius, C. Chevalier, and D. Ginsbourger, 2012: Changes in the odds of extreme events in the Atlantic basin depending on the position of the extratropical jet. Geophys. Res. Lett., 39, L22805, doi:10.1029/2012GL053993.

Mann, M. E., S. Rahmstorf, K. Kornhuber, B. A. Steinman, S. K. Miller, and D. Coumou, 2017: Influence of anthropogenic climate change on planetary wave resonance and extreme weather events. Sci. Rep., 7, 45 242, doi:10.1038/srep45242.

Marshall, A. G., D. Hudson, M. C. Wheeler, O. Alves, H. H. Hendon, M. J. Pook, and J. S. Risbey, 2014: Intra-seasonal drivers of extreme heat over Australia in observations and POAMA-2. Climate Dyn., 43, 1915-1937, doi:10.1007/ s00382-013-2016-1.

Martius, O., S. Pfahl, and C. Chevalier, 2016: A global quantification of compound precipitation and wind extremes. Geophys. Res. Lett., 43, 7709-7717, doi:10.1002/2016GL070017.
Miralles, D. G., A. J. Teuling, C. C. van Heerwaarden, and J. Vilà-Guerau de Arellano, 2014: Mega-heatwave temperatures due to combined soil desiccation and atmospheric heat accumulation. Nat. Geosci., 7, 345-349, doi:10.1038/ ngeo2141.

Nairn, J. R., and R. J. Fawcett, 2015: The excess heat factor: A metric for heatwave intensity and its use in classifying heatwave severity. Int. J. Environ. Res. Public Health, 12, 227-253, doi:10.3390/ijerph120100227.

Nicholls, N., and S. Larsen, 2011: Impact of drought on temperature extremes in Melbourne, Australia. Aust. Meteor. Oceanogr. J., 61, 113-116, doi:10.22499/2.6102.003.

Parker, T. J., G. J. Berry, and M. J. Reeder, 2013: The influence of tropical cyclones on heat waves in southeastern Australia. Geophys. Res. Lett., 40, 6264-6270, doi:10.1002/ 2013GL058257.

- — - — , and N. Nicholls, 2014: Modes of climate variability and heat waves in Victoria, southeastern Australia. Geophys. Res. Lett., 41, 6926-6934, doi:10.1002/ 2014 GL061736.

Pastor, M. A., and M. J. Casado, 2012: Use of circulation types classifications to evaluate AR4 climate models over the EuroAtlantic region. Climate Dyn., 39, 2059-2077, doi:10.1007/ s00382-012-1449-2.

Perkins, S. E., and L. V. Alexander, 2013: On the measurement of heat waves. J. Climate, 26, 4500-4517, doi:10.1175/ JCLI-D-12-00383.1.

—, D. Argüeso, and C. J. White, 2015: Relationships between climate variability, soil moisture, and Australian heatwaves. J. Geophys. Res. Atmos., 120, 8144-8164, doi:10.1002/ 2015JD023592.

Perkins-Kirkpatrick, S. E., and Coauthors, 2016: Natural hazards in Australia: Heatwaves. Climatic Change, 139, 101-114, doi:10.1007/s10584-016-1650-0.

Pezza, A. B., P. van Rensch, and W. Cai, 2012: Severe heat waves in southern Australia: Synoptic climatology and large scale connections. Climate Dyn., 38, 209-224, doi:10.1007/ s00382-011-1016-2.

Pfahl, S., and H. Wernli, 2012: Quantifying the relevance of atmospheric blocking for co-located temperature extremes in the Northern Hemisphere on (sub-)daily time scales. Geophys. Res. Lett., 39, L12807, doi:10.1029/2012GL052261.

Purich, A., T. Cowan, W. Cai, P. van Rensch, P. Uotila, A. Pezza, G. Boschat, and S. Perkins, 2014: Atmospheric and oceanic conditions associated with southern Australian heat waves: A CMIP5 analysis. J. Climate, 27, 7807-7829, doi:10.1175/ JCLI-D-14-00098.1.

Quesada, B., R. Vautard, P. Yiou, M. Hirschi, and S. I. Seneviratne, 2012: Asymmetric European summer heat predictability from wet and dry southern winters and springs. Nat. Climate Change, 2, 736-741, doi:10.1038/nclimate1536.

Reichle, R. H., Q. Liu, R. D. Koster, C. S. Draper, S. P. P. Mahanama, and G. S. Partyka, 2017: Land surface precipitation in MERRA-2. J. Climate, 30, 1643-1664, doi:10.1175/JCLI-D-16-0570.1.

Röthlisberger, M., S. Pfahl, and O. Martius, 2016: Regional-scale jet waviness modulates the occurrence of midlatitude weather extremes. Geophys. Res. Lett., 43, 10 989-10 997, doi:10.1002/ 2016 GL070944.

Scaife, A. A., T. Woollings, J. Knight, G. Martin, and T. Hinton, 2010: Atmospheric blocking and mean biases in climate models. J. Climate, 23, 6143-6152, doi:10.1175/ 2010JCLI3728.1. 
Seneviratne, S. I., T. Corti, E. L. Davin, M. Hirschi, E. B. Jaeger, I. Lehner, B. Orlowsky, and A. J. Teuling, 2010: Investigating soil moisture-climate interactions in a changing climate: A review. Earth-Sci. Rev., 99, 125-161, doi:10.1016/ j.earscirev.2010.02.004.

, M. G. Donat, A. J. Pitman, R. Knutti, and R. L. Wilby, 2016: Allowable $\mathrm{CO}_{2}$ emissions based on regional and impactrelated climate targets. Nature, 529, 477-483, doi:10.1038/ nature 16542.

Shepherd, T. G., 2014: Atmospheric circulation as a source of uncertainty in climate change projections. Nat. Geosci., 7, 703708, doi:10.1038/ngeo2253.

Sippel, S., J. Zscheischler, M. D. Mahecha, R. Orth, M. Reichstein, M. Vogel, and S. I. Seneviratne, 2017: Refining multi-model projections of temperature extremes by evaluation against land-atmosphere coupling diagnostics. Earth Syst. Dyn., 8, 387-403, doi:10.5194/esd-8-387-2017.
Teng, H., G. Branstator, G. A. Meehl, and W. M. Washington, 2016: Projected intensification of subseasonal temperature variability and heat waves in the Great Plains. Geophys. Res. Lett., 43, 2165-2173, doi:10.1002/2015GL067574.

Wald, A., 1943: Tests of statistical hypotheses concerning several parameters when the number of observations is large. Trans. Amer. Math. Soc., 54, 426-482, doi:10.1090/ S0002-9947-1943-0012401-3.

Wallace, J. M., Q. Fu, B. V. Smoliak, P. Lin, and C. M. Johanson, 2012: Simulated versus observed patterns of warming over the extratropical Northern Hemisphere continents during the cold season. Proc. Natl. Acad. Sci. USA, 109, 14337-14342, doi:10.1073/pnas.1204875109.

Wilks, D. S., 2016: "The stippling shows statistically significant grid points": How research results are routinely overstated and overinterpreted, and what to do about it. Bull. Amer. Meteor. Soc., 97, 2263-2273, doi:10.1175/BAMS-D-15-00267.1. 